\title{
FUTEBOL, HISTÓRIA E POLÍTICA
}

\author{
Football, history and politics
}

Fútbol, historia y política

\author{
BERNARDo Borges BUARQUE DE HOLLANDA ${ }^{\text {I* }^{*}}$ \\ JOÃO MARCELO EHLERT MAIA ${ }^{\text {I* }}$ \\ THAIS CONTINENTINO BLANK ${ }^{*}$
}

EDITORES

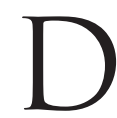

ossiês temáticos têm-se mostrado de grande importância para o desenvolvimento dos estudos sobre esportes e futebol nas Ciências Humanas e Sociais brasileiras. Desde pelo menos 0 ano de 1994, com o dossiê organizado pela Revista USP (n. 22 - Futebol), assistiu-se a uma série de publicações em periódicos científicos sobre esse tema no país. Com base em números especiais, textos e autores tornaram-se referência e fonte recorrente de citações. Deste modo, contribuíram para a formação de um campo de estudos e possibilitaram um avanço reflexivo — teórico, metodológico e empírico — em torno das práticas esportivas nacionais e internacionais.

DOI: http://dx.doi.org/10.1590/s2178-14942019000300001

\footnotetext{
'Escola de Clências Sociais da Fundação Getulio Vargas (CPDOC/FGV), Rio de Janeiro - RJ, Brasil.

*Professores da Escola de Ciências Sociais da Fundação Getulio Vargas (CPDOC/FGV) e Editores da Revista Estudos Históricos (bernardo.hollanda@fgv.br; joao.maia@fgv.br; thais.blank@fgv.br)

https://orcid.org/0000-0001-7781-4684; https://orcid.org/0000-0002-3330-871X; https://orcid.org/0000-0002-1470-9999
} 
A própria revista Estudos Históricos contribuiu nesse sentido em 1999, quando publicou o número 23 - Esporte e Lazer — conhecido por trazer à tona debates e por ensejar polêmicas acerca dos referenciais mais apropriados para pesquisas na área. A "década esportiva", como ficou conhecido o período entre 2007 e 2016, com a realização de uma gama de megaeventos esportivos no Brasil, estimulou também um conjunto significativo de dossiês dessa natureza, publicados em congêneres como a Horizontes Antropológicos, a Revista de História (USP) e os Cadernos AEL (Unicamp), entre outros periódicos científicos.

Passados os megaeventos, e multiplicadas as pesquisas sobre modalidades esportivas em programas de pós-graduação no país, novas gerações continuam a se debruçar sobre esse fenômeno típico das sociedades modernas e contemporâneas, capaz de mobilizar identidades coletivas, interesses midiáticos, circulações globais, fluxos financeiros e representações sociais. A motivação para a organização de um número específico dedicado à temática futebolística, cuja importância no século XX permanece atual, relaciona-se também a um cenário de desafios políticos que se colocam para a sociedade brasileira, na esteira das chamadas Jornadas de Junho de 2013 e no conturbado ciclo jurídico-político que se sucede ao Brasil pós-megaeventos.

O presente dossiê propõe, pois, uma articulação entre três dimensões — Futebol, História e Política. Estas inspiram-se, por sua vez, no trabalho desenvolvido pelo saudoso colega Carlos Eduardo Sarmento (2013), pioneiro no CPDOC nos estudos futebolísticos. Em sua investigação sobre a história institucional do futebol, feita com fontes primárias junto aos arquivos da Confederação Brasileira de Desportos (CBD), Sarmento tratou da constituição da identidade nacional por meio da Seleção Brasileira e propôs intersecções diacrônicas desta com entidades desportivas, com instituições de poder e com estruturas políticas em chave mais ampla.

A tríade que circunscreve o presente número permite igualmente arejar um assunto marcado pelo peso ceticista das Teorias Críticas do Esporte, muito presentes nas Ciências Sociais europeias, norte-americanas e sul-americanas entre os anos 1960 e 1980, a exemplo dos escritos de Jean-Marie Bhrom (2006), Gerhard Vinnai (1973), Bero Rigauer (1981) e Juan José Sebreli (2005).

Se a introdução dos estudos sobre futebol no Brasil precisou contornar tais críticas funcionalistas e frankfurtianas, que preconizavam sua condição seja de dominação instrumental seja de epifenômeno da ideologia capitalista, valeu-se para tanto das postulações da Antropologia Social na afirmação da relevância do objeto no decorrer dos anos 1980. Rito, mito e símbolo das sociedades complexas foram, então, mobilizados para observar processos constitutivos da identidade nacional, em particular o significado, ora metafórico ora metoními- 
co, adquirido pelo selecionado brasileiro nos eventos quadrienais das Copas do Mundo FIFA, com seus sentidos amplificados e conduzidos pelas narrativas da imprensa.

Assim, de tema secundário e por vezes não sério, o futebol pouco a pouco conquistou sua legitimidade e alcançou sua institucionalização na Academia. Nos últimos anos, observa-se também uma diversificação de abordagens, com a capacidade de ir além do âmbito meramente identitário e culturalista. No terreno da historiografia, a história social tem-se apropriado da temática em períodos mais recentes, graças a trabalhos seminais como o de Leonardo Pereira (2001). É o caso de destacar também a história política, cuja renovação nos anos 1980 (Rémond, 2003), se ainda é tímida na oferta de pesquisas concretas sobre o assunto, pavimenta caminhos para um tratamento menos canônico nessa área.

A proposta de renovar olhares acerca da história política do futebol é, portanto, um objetivo que se procurou contemplar com o presente volume. Da mesma maneira que as edições anteriores de Estudos Históricos, a grande demanda recebida e o elevado número de artigos aprovados, acima do que se poderia afinal publicar, foram uma prova do número de pesquisas de qualidade existentes nos dias de hoje, não só no Brasil como na comunidade acadêmica internacional. A difícil tarefa de selecionar ao final os textos por publicar sinaliza para a existência de um alargamento e uma continuidade geracional de pesquisadores que vêm se formando nas últimas décadas.

Sendo assim, o presente dossiê é constituído por três partes principais. A primeira conta com os sete artigos selecionados após o processo de avaliação cega por pares. Trata-se de doutorandos e doutores, vinculados a programas de pós-graduação no Brasil, em sua maioria historiadores, mas também de sociólogos, urbanistas e pesquisadores da área de Educação Física.

A primeira parte é composta por textos de autoria de João Malaia (Dep. História/Universidade Federal de Santa Maria); Marcel Tonini (Dr. História/Universidade de São Paulo) e Sérgio Giglio (Dep. Ed. Física/Universidade Estadual de Campinas); Raphael Rajão (Doutorando em História/FGV CPDOC); Luís Burlamaqui Rocha (Dr. em História/USP); Lívia Magalhães (Instituto de História/Universidade Federal Fluminense); Erick Melo (IPPUR/Universidade Federal do Rio de Janeiro) e Gabriel Cid (Dr. IESP/Universidade do Estado do Rio de Janeiro).

Salienta-se, ainda na primeira parte, a colaboração de um autor de origem inglesa, Matthew Brown, professor de Letras Modernas na Universidade de Bristol, no Reino Unido. Agradecemos, a propósito, às dezenas de pareceristas ad hoc que contribuíram voluntariamente com sua expertise para a composição final dessa seção. 
A segunda parte abarca as colaborações especiais e traz os dois autores internacionais, convidados especialmente pela equipe editorial para publicarem no dossiê. São eles: Courtney Campbell, brasilianista de origem estadunidense, doutora em História pela Universidade de Vanderbilt (EUA) e professora da Universidade de Birmingham; e David Wood, latino-americanista de origem inglesa, responsável por presidir a Society for Latin American Studies (SLAS) no período 2017-2019, e professor da Universidade de Sheffield.

A terceira e última parte do número 68 de Estudos Históricos apresenta uma entrevista com Maria Lúcia Garcia Pallares-Burke, referência importante nas Ciências Históricas e Sociais, em particular no estudo da obra de Gilberto Freyre, destacando-se como pesquisadora associada há mais de vinte anos do Centro de Estudos Latino-Americanos da Universidade de Cambridge.

2019 foi um ano de perdas na área de estudos do futebol, com o falecimento de três pesquisadores referenciais: o sociólogo inglês Eric Dunning, o geógrafo Gilmar Mascarenhas e a antropóloga Simoni Lahud Guedes. À memória desses três estudiosos dedicamos este número.

Por fim, desejamos a todos uma boa leitura.

\section{REFERÊNCIAS BIBLIOGRÁFICAS}

BHROM, Jean-Marie; PERELMAN, Marc. Le football, une peste emotionelle. Paris: Gallimard, 2006.

PEREIRA, Leonardo Affonso de Miranda. Footballmania: uma história social do futebol no Rio de Janeiro (1902-1938). Rio de Janeiro: Nova Fronteira, 2000.

RÉMOND, René. Por uma história política. Rio de Janeiro: FGV Editora, 2003.

RIGAUER, Bero. Sport and work. New York: Columbia University Press, 1981.

SARMENTO, Carlos Eduardo. A construção da nação canarinho: uma história institucional da seleção brasileira de futebol, 1914-1970. Rio de Janeiro: FGV Editora, 2013.

SEBRELI, Juan José. La era del fútbol. Buenos Aires: Debolsillo, 2005.

VINNAI, Gerhard. Football mania: the players and the fans - the mass psychology of football. London: Orbach \& Chambers, 1973. 